\title{
Torsional resistance of three ProTaper rotary systems
}

\author{
Abdullah Alqedairi ${ }^{1}$, Hussam Alfawaz ${ }^{1}$, Bader Abualjadayel ${ }^{1}$, Mohammad Alanazi $^{1}$, Ahmad Alkhalifah ${ }^{1}$ and \\ Ahmed Jamleh ${ }^{2 *}$
}

\begin{abstract}
Background: The aim of this study is to compare the torsional resistance of the available ProTaper rotary systems, namely, ProTaper Universal (PTU), ProTaper Next (PTN), and ProTaper Gold (PTG).

Methods: A total of 195 files from the three systems distributed into 13 groups (PTU-S1, PTU-S2, PTU-F1, PTU-F2, PTU-F3, PTG-S1, PTG-S2, PTG-F1, PTG-F2, PTG-F3, PTN-X1, PTN-X2 and PTN-X3) were subjected to torsional fatigue until failure. The torsional test was performed according to ISO 3630-1, where each file was placed in a straight position to eliminate the influence of cyclic fatigue. The Kruskal-Wallis test was conducted to compare the mean maximum torques and angular deflections at fracture for the groups, and the Mann-Whitney test was performed for pairwise comparisons. The significance level was set at 0.05 and the fractured surfaces were examined under a scanning electron microscope.
\end{abstract}

Result: Among the tested files, PTG-S1 had the lowest torsional fatigue resistance, whereas PTU-F2 and PTU-F3 had the highest torsional resistance. The scanning electron microscope showed typical features of torsional failure.

Conclusion: The new ProTaper systems (PTG and PTN) did not show improved torsional resistance in comparison with PTU.

Keywords: ProTaper gold, ProTaper next, ProTaper universal, Scanning electron microscope, Torsional resistance

\section{Background}

Currently, the mechanical preparation of the root canal system can be performed safely with the use of nickel titanium (NiTi) rotary files. This rotary file's flexibility showed a huge improvement in endodontic treatment, wherein it can prepare the root canal quickly with less iatrogenic errors while maintaining the original canal anatomy $[1,2]$. Despite these benefits, the NiTi file can fracture unexpectedly, which is a complication that adversely affects the prognosis [3]. Any preparation stress induced on the file can result in file strain, which leads to fatiguing and eventually file fracture, especially when the stress exceeds the strength of the NiTi file. File fatigue is a well-known mechanism for file fracture caused by cyclic fatigue, torsional failure, or both [4]. Cyclic

\footnotetext{
* Correspondence: aojamleh@gmail.com

${ }^{2}$ King Abdullah International Medical Research Centre, Restorative and

Prosthetic Dental Sciences, College of Dentistry, Ministry of National Guard Health Affairs, King Saud bin Abdulaziz University for Health Sciences, P.O. Box 22490, Riyadh 11426, Saudi Arabia

Full list of author information is available at the end of the article
}

fatigue occurs while the file rotates in a curved geometry, wherein the stress is at its highest at the area of maximum curvature, producing alternating compression and tension cycles until fracture [5, 6]. Torsional fatigue failure occurs when the torque resulting from contact between the file and canal wall exceeds the torsional strength of the file, or by twisting the file through its longitudinal axis at one end while the tip or another part of the file is locked in the canal $[1,4,7]$. The lifetime of NiTi files may be influenced by many factors, such as file geometry, metal surface treatment, thermal treatment, and metallurgic characterization of the NiTi alloys [8-11].

Increasing the resistance to file fracture has been the main goal of manufacturers in developing new file systems to improve the safety and effectiveness of canal preparation through innovative design and manufacturing processes [12-14]. Modification in the manufacturing process or the use of new alloys, changing the taper over the length of the cutting blades, and adjusting the

(c) The Author(s). 2019 Open Access This article is distributed under the terms of the Creative Commons Attribution 4.0 International License (http://creativecommons.org/licenses/by/4.0/), which permits unrestricted use, distribution, and reproduction in any medium, provided you give appropriate credit to the original author(s) and the source, provide a link to the Creative Commons license, and indicate if changes were made. The Creative Commons Public Domain Dedication waiver (http://creativecommons.org/publicdomain/zero/1.0/) applies to the data made available in this article, unless otherwise stated. 
instrument's cross-sectional design are methods used to enhance the file's clinical performance [12, 15, 16].

Currently, three ProTaper rotary systems (Dentsply Sirona) are available in the market, namely, ProTaper Universal (PTU), ProTaper Next (PTN), and ProTaper Gold (PTG). PTU is manufactured from super-elastic conventional NiTi alloy. It has shaping (S1 (size 17, .02 taper) and S2 (size 20, .04 taper)) and finishing (F1 (size 20, .07 taper), F2 (size 25, .08 taper), and F3 (size 30, .09 taper)) files. PTN is manufactured from martensitic (MWire) NiTi alloy subjected to thermo-mechanical processing. It has X1 (size 17, .04 taper), X2 (size 25, .06 taper), and $\mathrm{X} 3$ (size 30, .07 taper) files. The design of these files is different from that of the PTU files. The PTN files include variable tapers and an off-centered rectangular cross-section. The martensitic wire technology, in combination with the unique design, was shown to enhance flexibility and fracture resistance [17, 18]. The action of X1 can replace PTU-S1, PTU-S2, and PTU-F1 files [19]. Recently, ProTaper Gold (PTG) has been introduced and it has the same design, geometry, and features as those of the PTU files. However, it has been developed with proprietary advanced metallurgy from Gold-wire NiTi, which makes it more flexible than PTU [18, 20, 21].

Torsional resistance is one of the most significant mechanical properties of the NiTi alloy, which can affect the clinical performance of endodontic files, especially in narrow canals. Previous studies have tested the torsional resistance of specific sizes of the ProTaper systems [16, 17, 20, 22-27]. However, investigating the torsional behavior of the commonly used series of files of the available ProTaper systems has not been addressed adequately. Thus, the present study was conducted to compare the torsional fatigue resistance of the ProTaper files of different systems, namely, the conventional wire, M-Wire, and Gold-wire NiTi. The null hypothesis was that there is no difference in the torsional resistance among the tested ProTaper files.

\section{Methods}

A total of 195 new files distributed into 13 groups (PTU-S1, PTU-S2, PTU-F1, PTU-F2, PTU-F3, PTN-X1, PTN-X2, PTN-X3, PTG-S1, PTG-S2, PTG-F1, PTG-F2, and PTG-F3) $(n=15)$ were used for torsional evaluation.

The torsional test was conducted according to ISO 3630-1 (International Organization for Standardization, 1992) [28] by using a torsion tester (WP 500 torsion tester-30 Nm, Gunt Hamburg, Germany). A portion of 3 $\mathrm{mm}$ from the file tip was clamped with a pin vise. The file was rotated clockwise as viewed from the shank end and the test speed was set to $2 \mathrm{rpm}$. The device was calibrated before the test. The torques at failure and maximum angular deflections were recorded.
Fractured files with the highest and lowest torque values from each group, totaling 26 files, were selected for fractographic analysis by using a scanning electron microscope (SEM; JEOL 6360LV Scanning Electron Microscope, Japan). Each file was cleaned in absolute alcohol and fixed on a metallic stub to evaluate the fracture area at 200X, 500X, and 1000X magnification levels.

An additional new specimen of each file type (13 in total) was sectioned at $3 \mathrm{~mm}$ from the tip (D3) to observe and measure the cross-sectional surface area under a stereomicroscope.

\section{Statistical analysis}

Because the torque distributions at failure and angular deflection were found to be abnormal by the ShapiroWilk test $(P=0.000)$, the Kruskal-Wallis and MannWhitney tests were conducted to determine the statistical significance among the tested groups. The significance was determined at a $5 \%$ level.

\section{Results}

The results of the torsional tests are summarized in Table 1 , which present the mean ( \pm standard deviation), median, and range values of both torque at failure and angular deflection at failure of the tested file types.

Amongst all the tested files, PTG-S1 and PTU-F3 demonstrated the lowest and highest torque at failure, respectively $(P<0.05)$. There was a tendency of torque at failure increasing as the file cross-sectional area increased (Table 1). Within each system, there were significant differences between all the file types, except between PTU-S1 and PTU-F1 and PTU-S2 and PTU-F1, and between PTG-F1 and PTG-F2, which were found to be comparable.

The comparison of the PTU and PTG shaping files revealed that the PTU-S1 and PTU-S2 files had significantly higher torsional failure resistance than the PTGS1 and PTG-S2 files, respectively $(P<0.01)$. In the comparison of the PTU-F1, PTG-F1, and PTN-X1 files, the PTN-X1 was found to have significantly the lowest torsional resistance $(P<0.001)$, whereas the PTU-F1 and PTG-F1 files had comparable values $(P=0.74)$. The comparison of the PTU-F2, PTG-F2, and PTN-X2 files revealed that the PTN-X2 file had a significantly lower torsional resistance than the PTU-F2 file $(P<0.001)$. In the comparison of the PTU-F3, PTG-F3, and PTN-X3 files, the PTN-X3 was found to have significantly the lowest torsional resistance, followed by the PTG-F3 and PTU-F3 files $(\mathrm{P}<0.001)$.

When a similar analysis was performed for angular deflection at fracture (Table 1), it was found that the PTU-F3 and PTG-F3 files were comparable and had significantly the highest angular deflection values $(P<0.05)$. The three PTN files showed comparable results and had 
Table 1 Descriptive data of the torque at failure and angular deflection in the tested systems

\begin{tabular}{|c|c|c|c|c|c|c|c|c|}
\hline & & \multirow{2}{*}{$\begin{array}{l}\text { Surface } \\
\text { area at } \\
\text { D3 } \\
\left(\mathrm{mm}^{2}\right)\end{array}$} & \multicolumn{3}{|c|}{ Torque at failure $(\mathrm{gcm})$} & \multicolumn{3}{|c|}{ Angular deflection (degree) } \\
\hline & & & Mean \pm SD & Median & Range & Mean \pm SD & Median & Range \\
\hline \multirow[t]{5}{*}{$\overline{\text { PTU }}$} & S1 & 0.022 & $68.8 \pm 25.1$ & $77.6^{\text {af }}$ & $25.5-101.2$ & $347.9 \pm 37.6$ & $355^{\text {aeg }}$ & $270-420$ \\
\hline & $\mathrm{S} 2$ & 0.024 & $112.5 \pm 30.5$ & $108.6^{b}$ & $60.6-182.2$ & $367 \pm 48.5$ & $365^{\text {af }}$ & 290-495 \\
\hline & $\mathrm{F} 1$ & 0.048 & $100.6 \pm 36.4$ & $93.9^{\mathrm{abg}}$ & $63.3-169.8$ & $380.3 \pm 48.1$ & $375^{\text {bf }}$ & $295-480$ \\
\hline & $\mathrm{F} 2$ & 0.121 & $141.7 \pm 37.6$ & $136.3^{c}$ & $90.82-235.5$ & $346.7 \pm 56.6$ & $350^{\text {aeg }}$ & $275-470$ \\
\hline & F3 & 0.149 & $196.2 \pm 20.9$ & $189.8^{d}$ & $168.4-250.8$ & $559 \pm 62.4$ & $540^{c}$ & $450-690$ \\
\hline \multirow[t]{5}{*}{ PTG } & S1 & 0.022 & $43.4 \pm 14.9$ & $41.6^{\mathrm{e}}$ & $22.2-80$ & $361.7 \pm 53.1$ & $370^{\text {abdef }}$ & $280-440$ \\
\hline & $\mathrm{S} 2$ & 0.024 & $73.7 \pm 33.3$ & $66.3^{f}$ & $37.4-179.0$ & $331.0 \pm 39.9$ & $335^{\mathrm{e}}$ & $260-385$ \\
\hline & $\mathrm{F} 1$ & 0.048 & $94 \pm 23.1$ & $91.4^{\mathrm{b}}$ & $37.8-129.4$ & $393.2 \pm 60.6$ & $390^{f}$ & $285-495$ \\
\hline & $\mathrm{F} 2$ & 0.121 & $117.4 \pm 32$ & $115.5^{\mathrm{bcg}}$ & $70.6-201.2$ & $371.3 \pm 50.4$ & $370^{f g}$ & 280-495 \\
\hline & F3 & 0.149 & $166.4 \pm 17.2$ & $167.4^{\mathrm{h}}$ & $135.1-194.5$ & $580.3 \pm 61.7$ & $580^{c}$ & $480-670$ \\
\hline \multirow[t]{3}{*}{ PTN } & $\mathrm{X}_{1}$ & 0.048 & $59.9 \pm 13.5$ & $58.8^{f}$ & $36.7-82.2$ & $291.6 \pm 35.8$ & $280^{h}$ & $220-360$ \\
\hline & $\times 2$ & .094 & $95.8 \pm 38.9$ & $92 a^{b}$ & $44.3-185.1$ & $303.1 \pm 32.5$ & $310^{\mathrm{h}}$ & $245-355$ \\
\hline & X3 & 0.137 & $115.4 \pm 17.6$ & $116.7^{i}$ & $81.4-142.9$ & $303.7 \pm 26.3$ & $300^{h}$ & $270-355$ \\
\hline
\end{tabular}

Different superscripts indicate statistical significance

significantly the lowest angular deflections in comparison with the other file types $(P<0.05)$.

Under the SEM, all the instruments exhibited similar torsional fatigue behavior. The fractured cross-sectional surfaces revealed typical features of torsional failure, including concentric abrasion pattern, and a dimpled surface with micro-voids in the middle (Fig. 1).

At D3, the surface areas of S1, S2, F1, F2, and F3 in PTU and PTG were 0.022, 0.024, 0.048, 0.121, and $0.149 \mathrm{~mm}^{2}$, respectively, whereas the PTN-X1, PTN-X2, and PTN-X3 had surface areas of 0.48, 0.094, and $0.137 \mathrm{~mm}^{2}$, respectively (Table 1 ).

\section{Discussion}

Differences among the torsional resistance data of the tested files were detected during evaluation. PTG-S1 and PTU-F3 showed the lowest and highest torque at failure values, respectively (Table 1 ). Furthermore, the lowest angular deflections were detected with the three PTN files. Therefore, the null hypothesis was rejected.

Torsional strength indicates the file ability to get twisted before fracture occurs. This property was shown to be influenced by many factors, such as file size, design, alloy's chemical composition, and manufacturing processes [29-31]. Within each group, it was found that the maximum torque increased as the file size increased. Furthermore, the tested PTN files (X1, X2, and X3) revealed lower torsional resistances than their respective PTU and PTG files (F1, F2, and F3). These findings could be attributed to the file design and cross-sectional area, where PTN has a rectangular cross section whereas the PTU and PTG have convex triangular cross-sections.
These observations are consistent with those of previous studies, wherein an increase in the central core diameter of the files was reported to enhance its resistance to the torsional stress [16, 17, 22, 23, 25, 27, 32]. However, another study found that the PTN-X2 had the highest torsional resistance, followed by PTU-F2 and PTG-F2 [24]. This conflict may be due to the study design, where they used a different device that was not compatible with the ISO 3630-1 specification. Besides that, they claimed that the off-centered cross-sectional design could be the main reason for the improved torsional behavior. However, the in vitro torsional testing performed does not provide a suitable condition to test the effect of file geometry. Rather, it provides file behavior at the area where it is held. In this study, the surface areas of the files were measured in the area subjected to torsional fatigue and it was found that the PTN files have smaller surface areas than their corresponding file types in PTU and PTG. Moreover, alterations in file taper might explain the differences in torsional behavior.

The manufacturing process, alloy properties and thermal treatment could influence the fatigue resistance behaviors of rotary files [18]. Thermal treatment of NiTi alloy is considered one of the most effective methods to enhance and modify the mechanical properties of the alloy [20]. The present results showed that PTU files had higher torsional resistance than their respective PTG files except F1 and F2 files. Similarly, Elnaghy and Elsaka [20] reported that the PTG-F2 file did not show improved resistance to torsional stress in comparison with the PTU-F2 file. However, Kaval et al. [26] found that the PTG-F2 files had a higher torsional resistance 


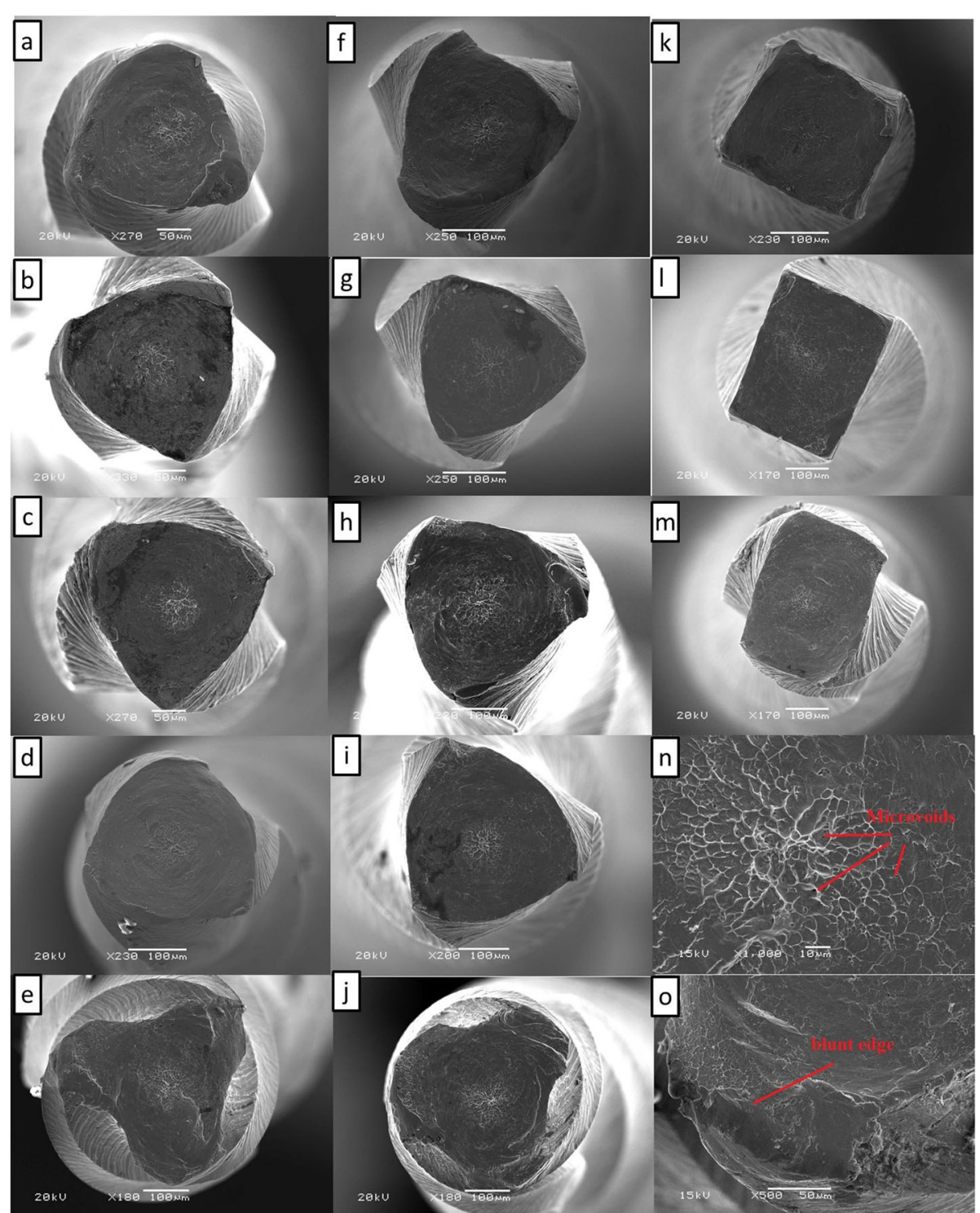

Fig. 1 Scanning electron microscopic images of ProTaper Universal, ProTaper Gold, and ProTaper Next instruments after the torsional resistance testing revealing circular abrasion streaks and skewed dimples in the center of the fractured surfaces. a PTU-S1, b PTU-S2, c PTU-F1, d PTU-F2, e PTU-F3, $\mathbf{f}$ PTG-S1, $\mathbf{g}$ PTG-S2, $\mathbf{h}$ PTG-F1, i PTG-F2, $\mathbf{j}$ PTG-F3, $\mathbf{k}$ PTN-X1, I PTN-X2, and $\mathbf{m}$ PTN-X3. $\mathbf{n}$ and $\mathbf{o}$ show the fracture characteristics that occurred after the torsional resistance testing

than the PTU-F2 files. Although alterations in the manufacturing process enhanced the cyclic fatigue resistance of PTG [20, 26, 33] and made its files more flexible than the PTU files [18, 20, 21], it did not improve the torsional behavior. This may be attributed to manufacturing process of the PTG files to keep them at martensitic phase at body temperature with advanced metallurgy and special thermal treatment [18]. This allows to have a greater amount of deformation than the conventional NiTi alloy [16].

Although higher angular deflection of the file before the fracture could be beneficial to prevent intracanal fracture, it may have no clinical significance because one complete rotation will occur in $0.2 \mathrm{~s}$ at a speed of $300 \mathrm{rpm}$ [34]. Moreover, in agreement with the previous studies, the angular deflection measurements did not correlate with their corresponding torque at failure values [35].

It is noteworthy that the current study subjected 3 ProTaper systems to the same experimental setting. Although the present methodology does not mimic the clinical setting, the findings could give information about which file system can be used based on the canal geometry. Evaluating the mechanical properties of the NiTi files and their performance is essential for clinicians to select the system that improves clinical outcomes [14]. 
Once the torsional strength of the file is exceeded, intracanal file fracture can occur [4]. Clinically, the fracture can be caused due to the frictional forces generated between the file and root canal dentin, whereby preparation of narrow and constricted canals can subject rotary NiTi instruments to high torsional loads, mainly with small instruments and in the apical third of the canals [36]. In such conditions, the conventional PTU files with their high torsional resistance are suggested for use to avoid the intracanal file fracture $[27,37]$.

\section{Conclusions}

This study evaluated the torsional resistance of different ProTaper systems that are currently used by clinicians. Differences were detected among the torsional resistance data of the tested files. The results showed that the PTG-S1 and PTU-F3 had the lowest and highest torque at failure values, respectively. The lowest angular deflections were detected with the three PTN files. Within the limitations of this study, the new ProTaper systems did not show higher torque at failure data in comparison with PTU.

\section{Abbreviations}

NiTi: nickel titanium; PTG: ProTaper Gold; PTN: ProTaper Next; PTU: ProTaper Universal; SEM: scanning electron microscope

\section{Acknowledgements}

The authors thank College of Dentistry Research Center, King Saud

University, for their support in conducting this project (IR 0181).

\section{Authors' contributions}

$A A Q$ and $H A$ designed and conducted the experiment and wrote and edited the manuscript. MA, BA and AA participated in conducting the experiment. AJ analyzed and interpreted the data, and wrote and edited the manuscript. All authors read and approved the final manuscript.

\section{Funding}

Not funded.

\section{Availability of data and materials}

The datasets used and/or analysed during the current study are available from the corresponding author on reasonable request.

\section{Ethics approval and consent to participate}

Not applicable.

\section{Consent for publication}

Not applicable.

\section{Competing interests}

The authors declare that they have no competing interests.

\section{Author details}

'Department of Restorative Dental Sciences, College of Dentistry, King Saud University, Riyadh, Kingdom of Saudi Arabia. ${ }^{2}$ King Abdullah International Medical Research Centre, Restorative and Prosthetic Dental Sciences, College of Dentistry, Ministry of National Guard Health Affairs, King Saud bin Abdulaziz University for Health Sciences, P.O. Box 22490, Riyadh 11426, Saudi Arabia
Received: 25 February 2018 Accepted: 12 June 2019

Published online: 21 June 2019

\section{References}

1. Glossen C, Haller R, Dove S, del Rio C. A comparison of root canal preparations using $\mathrm{Ni}-\mathrm{Ti}$ hand, Ni-Ti engine-driven, and $\mathrm{K}$-flex endodontic instruments. J Endod. 1995:21:146-51.

2. Thompson SA. An overview of nickel-titanium alloys used in dentistry. Int Endod J. 2000:33:297-310

3. Panitvisai P, Parunnit P, Sathorn C, Messer H. Impact of a retained instrument on treatment outcome: a systematic review and meta-analysis. $J$ Endod. 2010;36:775-80.

4. Sattapan B, Nervo G, Palamara J, Messer H. Defects in rotary nickel-titanium files after clinical use. J Endod. 2000;26:161-5.

5. Pruett J, Clement D, Carnes D. Cyclic fatique testing of nickel-titanium endodontic instruments. J Endod. 1997;23:77-85.

6. Jamleh A, Sadr A, Nomura N, Yahata Y, Ebihara A, Hanawa T, Tagami J, Suda $\mathrm{H}$. Nano-indentation testing of new and fractured nickel-titanium endodontic instruments. Int Endod J. 2012;45:462-8.

7. Jamleh A, Sadr A, Nomura N, Ebihara A, Yahata Y, Hanawa T, Tagami J, Suda $\mathrm{H}$. Endodontic instruments after torsional failure: nanoindentation test. Scanning. 2014:36:437-43.

8. Yao J, Schwartz S, Beeson T. Cyclic fatigue of three types of rotary nickeltitanium files in a dynamic model. J Endod. 2006:32:55-7.

9. Bui T, Mitchell J, Baumgartner J. Effect of electropolishing ProFile nickeltitanium rotary instruments on cyclic fatigue resistance, torsional resistance, and cutting efficiency. J Endod. 2008:34:190-3.

10. Ebihara A, Yahata Y, Miyara K, Nakano K, Hayashi Y, Suda H. Heat treatment of nickel-titanium rotary endodontic instruments: effects on bending properties and shaping abilities. Int Endod J. 2011;44:843-9.

11. Ounsi H, Al-Shalan T, Salameh Z, Grandini S, Ferrari M. Quantitative and qualitative elemental analysis of different nickel-titanium rotary instruments by using scanning electron microscopy and energy dispersive spectroscopy. J Endod. 2008;34:53-5.

12. Gambarini $G$, Grande NM, Plotino $G$, et al. Fatigue resistance of enginedriven rotary nickel-titanium instruments produced by new manufacturing methods. J Endod. 2008:34:1003-5.

13. Gutmann JL, Gao Y. Alteration in the inherent metallic and surface properties of nickel-titanium root canal instruments to enhance performance, durability and safety: a focused review. Int Endod J. 2012;45: $113-28$.

14. Gao Y, Gutmann JL, Wilkinson $\mathrm{K}$, et al. Evaluation of the impact of raw materials on the fatigue and mechanical properties of Profile vortex rotary instruments. J Endod. 2012:38:398-401.

15. Shen $Y$, Haapasalo M, Cheung GS, et al. Defects in nickel-titanium instruments after clinical use. Part 1: relationship between observed imperfections and factors leading to such defects in a cohort study. J Endod. 2009:35:129-32.

16. Park SY, Cheung GS, Yum J, Hur B, Park JK, Kim HC. Dynamic torsional resistance of nickel-titanium rotary instruments. J Endod. 2010:36:1200-4.

17. Elnaghy AM. Cyclic fatigue resistance of ProTaper next nickel-titanium rotary files. Int Endod J. 2014:47:1034-9.

18. Hieawy A, Haapasalo M, Zhou H, Wang ZJ, Shen Y. Phase transformation behavior and resistance to bending and cyclic fatigue of ProTaper gold and ProTaper universal instruments. J Endod. 2015:41:1134-8.

19. ProTaper next technique - advanced Endodontics. Available from: https:// www.endoruddle.com/tc2pdfs/137/PTNTechCard.pdf. Accessed 18 June 2019

20. Elnaghy AM, Elsaka SE. Mechanical properties of ProTaper gold nickeltitanium rotary instruments. Int Endod J. 2016;49:1073-8.

21. Uygun AD, Kol E, Topcu MK, Seckin F, Ersoy I, Tanriver M. Variations in cyclic fatigue resistance among ProTaper gold, ProTaper next and ProTaper universal instruments at different levels. Int Endod J. 2016:49:494-9.

22. Baek SH, Lee C, Versluis A, Kim B, Lee W, Kim H. Comparison of torsional stiffness of nickel-titanium rotary files with different geometric characteristics. J Endod. 2011:37:1283-6.

23. Goo H, Kwak S, Ha J, Pedullà E, Kim H. Mechanical properties of various heat-treated nickel-titanium rotary instruments. J Endod. 2017:43:1872-7.

24. Elnaghy A, Elsaka S. Laboratory comparison of the mechanical properties of TRUShape with several nickel-titanium rotary instruments. Int Endod J. 2017; 50:805-12. 
25. Xu X, Eng M, Zheng Y, Eng D. Comparative study of torsional and bending properties for six models of nickel-titanium root canal instruments with different cross-sections. J Endod. 2006;32:372-5.

26. Kaval M, Capar I, Ertas H. Evaluation of the cyclic fatique and torsional resistance of novel nickel-titanium rotary files with various alloy properties. J Endod. 2016:42:1840-3.

27. Pedullà E, Lo Savio F, Boninelli S, et al. Torsional and cyclic fatigue resistance of a new nickel-titanium instrument manufactured by electrical discharge machining. J Endod. 2016;42:156-9.

28. International Organization for Standardization. Dental Root-Canal instruments- part 1: files, reamers, barbed broaches, rasps, paste carriers, explorers and cotton broaches. Switzerland: ISO; 1992.

29. Kuhn G, Jordan L. Fatigue and mechanical properties of nickel-titanium endodontic instruments. J Endod. 2002;28:716-20.

30. Bahia MGA, Buono VTL. Decrease in the fatigue resistance of nickel-titanium rotary instruments after clinical use in curved root canals. Oral Surg Oral Med Oral Pathol Oral Radiol Endod. 2005;100:249-55.

31. Miyai K, Ebihara A, Hayashi y DH, Suda h YT. Influence of phase transformation on the torsional and bending properties of nickel-titanium rotary endodontic instruments. Int Endod J. 2006;39:119-26.

32. Kim TO, Cheung GS, Lee JM, Kim BM, Hur B, Kim HC. Stress distribution of three NiTi rotary files under bending and torsional conditions using a mathematic analysis. Int Endod J. 2009;42:14-21.

33. Plotino G, Grande N, Mercadé Bellido M, Testarelli L, Gambarini G. Influence of temperature on cyclic fatigue resistance of ProTaper gold and ProTaper universal rotary files. J Endod. 2017:43:200-2.

34. Ninan E, Berzins D. Torsion and bending properties of shape memory and superelastic nickel-titanium rotary instruments. J Endod. 2013;39:101-4.

35. Bahia MG, Dias RF, Buono VT. The influence of high amplitude cyclic straining on the behaviour of superelastic NiTi. Int J Fatigue. 2006;28:1087-91.

36. Alfouzan $\mathrm{K}$, Jamleh A. Fracture of nickel titanium rotary instrument during root canal treatment and re-treatment: a 5-year retrospective study. Int Endod J. 2018:51:157-63.

37. Pereira E, Viana A, Buono V, et al. Behavior of nickel-titanium instruments manufactured with different thermal treatments. J Endod. 2015;41:67-71.

\section{Publisher's Note}

Springer Nature remains neutral with regard to jurisdictional claims in published maps and institutional affiliations.

Ready to submit your research? Choose BMC and benefit from:

- fast, convenient online submission

- thorough peer review by experienced researchers in your field

- rapid publication on acceptance

- support for research data, including large and complex data types

- gold Open Access which fosters wider collaboration and increased citations

- maximum visibility for your research: over $100 \mathrm{M}$ website views per year

At $\mathrm{BMC}$, research is always in progress.

Learn more biomedcentral.com/submissions 